\title{
MALENTENDIDOS FRECUENTES ACERCA DEL FINANCIAMIENTO DE LA EDUCACIÓN SUPERIOR A NIVEL MUNDIAL ${ }^{1}$
}

\author{
D. Bruce Johnstone ${ }^{2}$
}

\begin{abstract}
RESUMEN
Este ensayo consolida, a partir de la experiencia internacional comparada y el conocimiento tanto teórico como práctico en materia de financiamiento de la educación superior, catorce proposiciones denominadas "malentendidos frecuentes acerca del financiamiento de la educación superior a nivel mundial". Los catorce malentendidos corresponden a débiles fundamentaciones técnicas y/o visiones ideologizadas respecto al financiamiento compartido de la educación superior; las cuales son refutadas en el artículo.
\end{abstract}

Palabras clave: educación superior, financiamiento, aranceles, gratuidad, ideología.

\section{COMMON MISUNDERSTANDINGS ABOUT THE FINANCING OF HIGHER EDUCATION WORLD WIDE}

\section{ABSTRACT}

This article consolidates, from comparative international experience and theoretical and practical knowledge on the financing of higher education, fourteen proposals named "common misunderstandings about the financing of higher education world wide". The fourteen misunderstandings relate to the weak technical grounds and/or ideological visions regarding shared financing of higher education; which are refuted in this article.

Keywords: higher education, financing, tuition, tuition-free, ideology.

1 Una versión de este documento fue publicada en chino como: "La política de la educación superior: malentendidos frecuentes acerca del financiamiento de la educación superior". Peking University Education Review, 2013, Issue 2, pp. 36-45.

2 Profesor Emérito de Servicio Distinguido en Educación Superior y Comparada de la Universidad Estatal de Nueva York (SUNY) en Buffalo y Director del Proyecto Internacional Comparativo sobre el Financiamiento y Accesibilidad de la Educación Superior. Contacto: dbj@buffalo.edu 


\section{Introducción}

El presente ensayo se basa en muchos años de trabajo como académico y consultor en temas de financiamiento, gobernanza y formulación de políticas públicas de educación superior a nivel internacional, intercalados con años de práctica como rector de un college y canciller de un amplio sistema universitario público. Esta trayectoria culminó con más de una década como Director del Proyecto Internacional Comparativo sobre el Financiamiento y Accesibilidad de la Educación Superior en la Universidad de Buffalo donde, junto con mis estudiantes, nos enfrentamos a un popurrí de temas como políticas para el financiamiento de colleges y universidades, acceso de los estudiantes, aranceles, ayudas financiera y créditos estudiantiles, todos asuntos muy controvertidos desde el punto de vista financiero, político e ideológico.

Es precisamente la mezcla de economía teórica con el mundo real del financiamiento y gestión de colleges y universidades, junto con el estudio internacional comparativo del financiamiento y acceso a la educación superior que han resultado ser para mí un campo tan fértil, tanto en la investigación como en la docencia. Durante el transcurso de este trabajo mis propias creencias se han visto sumamente cuestionadas, tal como lo han sido las creencias y prescripciones políticas de otros que yo mismo he desafiado, muchos de los cuales son amigos cuyo trabajo admiro y de quienes he aprendido mucho. Pero también a lo largo de este trabajo, que incluye investigación de políticas para el Banco Mundial, talleres patrocinados en Dar es Salaam, Nairobi, Arusha, Praga, Moscú y Wuhan, además de conferencias y cátedras en más de 40 ciudades y 36 países, me he encontrado con ciertas creencias -muchas de las cuales bien podrían ser válidas en algunos países, y todas con al menos una parte de verdad junto a muchos proponentes serios y reflexivos -que en mi opinión son en muchos sentidos incompletas o incorrectas, al menos como proposiciones generales para la orientación de políticas, especialmente en países de ingresos bajos y medios.

He clasificado catorce proposiciones como malentendidos frecuentes acerca del financiamiento de la educación superior a nivel 
mundial. Estas creencias, o proposiciones, son mucho más que falacias de hombres de paja. Las he oído y leído todas, muchas de parte de académicos, políticos y profesionales en ejercicio, quienes se oponen ideológicamente a los costos compartidos - o al cambio mundial en el financiamiento de los costos de la educación superior que ha pasado de ser predominante o exclusivamente aportado por los Estados o contribuyentes, a ser cubierto por padres y estudiantes- y no están convencidos de que los aranceles y los créditos estudiantiles sean imperativos de una política de educación superior para la mayoría de los países. Yo aún podría ser persuadido de lo correcto en algunas de estas proposiciones, pero en su mayoría creo que estas catorce proposiciones conducen frecuentemente a políticas erróneas e intentaré a continuación explicar por qué.

Malentendido frecuente 1: El cobro de aranceles en el sector público, junto con otras manifestaciones de la creciente privatización de la educación superior pública, constituye una sobreenfatización de los beneficios privados de la educación superior y una subapreciación (o incluso hasta una negación) de sus beneficios públicos o sociales.

Uno de los debates menos edificantes en el discurso acerca de la idoneidad del cobro de aranceles en la provisión de educación superior pública consiste en si los beneficios de la educación superior son públicos (o sociales) o privados. Obviamente, la educación superior involucra a ambos. Los beneficios privados para los estudiantes incluyen una mayor productividad y mayores ingresos durante su ciclo de vida, mayor estatus, prestigio e influencia sociopolítica, además de una mayor opción de carreras, compañeros, domicilios y otras opciones de vida. Los padres de los estudiantes también reciben beneficios, incluyendo la satisfacción de que sus hijos posean todas las ventajas mencionadas anteriormente, además de una mayor capacidad de que cuiden de ellos en su vejez si esto fuera necesario. Décadas de estudios han documentado e incluso intentado asignarles un valor monetario (a veces expresado como retorno de la inversión) a estos beneficios indiscutiblemente privados. Tales investigaciones invariablemente concluyen que los beneficios privados son generalmente altos, pero que también varían de acuerdo 
con el beneficio que se mida y con las características del estudiante, el programa y nivel del título, y el país. Pero tal vez la demostración más elocuente de los beneficios privados (o al menos de la percepción de los beneficios privados) consiste en el simple hecho de que padres y estudiantes en todo el mundo están pagando altas sumas de dinero -a instituciones públicas con aranceles, al igual que a instituciones privadas, y en opciones privadas pagadas (fee-paying tracks) dentro de instituciones públicas- con el fin de acceder a instituciones de educación superior.

Resulta igual de obvio que también existen beneficios públicos o sociales, o externalidades positivas de la educación superior, incluyendo el crecimiento económico y la prosperidad, además de una mejor calidad de vida y virtudes sociales y cívicas tales como la tolerancia y una mayor participación política, que generalmente se asume que se propagan hacia el resto de la población, y superan por mucho tanto a la cantidad de estudiantes que recibieron la educación superior, como a los beneficios privados supuestamente percibidos por ellos. De este modo, los beneficios de la educación superior no son, principalmente, privados o sociales. Los beneficios sociales son, más bien, extensiones de la gran mayoría (si bien no de todos) los beneficios privados de la educación superior pública y privada.

Si se supuso que los beneficios privados eran suficientes para inducir una cantidad óptima de educación superior (es decir, un número suficiente de estudiantes o egresados por programa y nivel de logro) y para que estos beneficios privados se distribuyeran en forma equitativa, entonces se podría suponer que el mercado es suficiente sin subsidios públicos, es decir, con aranceles suficientes para cubrir los costos y necesidades de ingreso para, al menos, la instrucción de pregrado sin subsidio público adicional (con la excepción del subsidio público mínimo para cubrir el riesgo de nopago requerido para otorgar créditos de estudio a todos quienes los requieran). No obstante, generalmente se supone, en prácticamente todos los países, que la educación cubierta en su totalidad mediante aranceles (ya sea provista en forma pública o privada y suponiendo suficientes contribuciones por parte de los padres o créditos a los estudiantes): 
- no generaría una cantidad suficiente de egresados de los colleges y universidades para lograr captar todas las externalidades o beneficios sociales, de la educación superior;

- sobre todo, no generaría una cantidad suficiente de egresados en campos específicos, en particular aquellos que producen algunos de los beneficios sociales más significativos (por ejemplo, enfermeras, profesores, científicos y académicos); y

- no abordaría las metas sociales de avance en equidad entre la gran cantidad de estudiantes potenciales provenientes de familias que no cuentan con la capacidad de pago de aranceles, incluso con préstamos y otras formas de ayuda financiera y, por lo tanto, no llevaría a la distribución equitativa de estudiantes y egresados, que se necesitaría para satisfacer las nociones ampliamente sostenidas de justicia social.

De este modo, todos los países reconocen la necesidad de tener colleges y universidades con subsidio público. Por cierto, hasta fines del siglo XX, virtualmente toda Europa, la mayor parte de América Latina y África, además de la Unión Soviética y China, junto con el resto del entonces mundo comunista, le proporcionaba a la mayoría de los estudiantes una educación superior gratuita o prácticamente gratuita. Sin embargo, con los niveles crecientes de matrícula, el rápido aumento de los costos y las necesidades de ingresos para la educación superior a fines del siglo XX y principios del siglo XXI, existen aranceles en colleges y universidades públicas - generalmente nominales o moderados-en casi todos los países, con excepción principalmente de los países nórdicos y algunos otros europeos como Suiza y de los Länder en Alemania, además de Rusia y demás países llamados en transición (o postcomunistas) que han mantenido un arancel bajo o inexistente para ciertos estudiantes, pero que cobran aranceles extremadamente altos a otros. En países con aranceles en el sector público, estos varían de nominales equivalentes a menos del 10\% del costo de la instrucción, moderados, que cubren aproximadamente $15 \%$ a $30 \%$, a altos, como ocurre en algunos estados de Estados Unidos, donde el arancel de pregrado corresponde a un 30\% o 40\% o incluso 45\% (Johnstone y Marcucci 2010b). Por lo tanto, la mayoría de los costos de la instrucción a nivel de pregrado en casi todos los países (además de casi todos los gastos en investigación y en servicio 
público) siguen siendo asumidos por los Estados y los contribuyentes. De esta manera, la existencia o el nivel de los aranceles -sean estos muy bajos, diferidos, o relativamente altos- poco o nada dice acerca de la apreciación de cualquier país respecto de los beneficios de la educación superior.

Malentendido frecuente 2: Los aranceles altos en el sector público (por ejemplo, en el rango del 30\% al 50\% del costo de la instrucción) reflejan un supuesto político/ideológico predominante de que la mayoría de los beneficios de la educación superior son privados. En forma similar, los aranceles bajos o inexistentes reflejan la visión de que los beneficios son predominantemente sociales o públicos.

Esta creencia frecuente, y al menos parcialmente errónea, vincula la presencia o ausencia (o el nivel de) de los aranceles con los supuestos políticos e ideológicos prevalecientes en un país acerca del valor relativo del sector público, el nivel adecuado de los impuestos directos e indirectos, y el papel del mercado versus la regulación y dirección del Estado. Hay claramente algo de cierto en esta asociación. Estados Unidos, Inglaterra, Australia y algunas provincias de Canadá poseen aranceles relativamente altos para sus colleges y universidades, y también tienden a acoger más fácilmente la privatización de los servicios públicos en general, exhiben una mayor confianza en los mercados, y eligen gobiernos a nivel nacional y estatal o provincial que promueven un Estado más reducido e impuestos más bajos.

Al mismo tiempo, la aceptación de aranceles altos para los colleges y universidades públicas en Estados Unidos se ha dado también durante gobiernos progresistas o de izquierda. Asimismo, la aceptación de aranceles en el sector público está muy influenciada por: a) el hecho de que la educación superior pública en Estados Unidos está bajo la jurisdicción de los diversos estados a los que en general se les prohíbe tener déficits en sus presupuestos operacionales y, por lo tanto, deben compensar las caídas en sus presupuestos estatales mediante los aranceles; b) el extenso y preponderante sector privado que durante mucho tiempo ha tenido aranceles mucho más altos y que además ha mantenido al público concientizado acerca de la 
existencia de aranceles y de la necesidad de planificar el financiamiento de la educación superior sus hijos; y c) un sistema establecido y bien financiado de becas y créditos para los estudiantes, proveniente de fuentes federales, estatales, institucionales y otras privadas, que en el año 2011 sumaba más de \$227 mil millones, de los cuales cerca de \$104 mil millones correspondía a créditos subsidiados determinados por la situación financiera y no subsidiados para los estudiantes (College Board, 2011).

Por el contrario, los países nórdicos, que constituyen el último bastión de una educación superior totalmente gratuita, traspasan la mayoría de los altísimos costos de la mantención de los estudiantes a los mismos estudiantes en forma de préstamos. Inglaterra y Australia, por otro lado, si bien se jactan de contar con universidades públicas gratuitas al momento de la matrícula, de hecho difieren sus considerables aranceles en forma de créditos adicionales para los estudiantes. Por último, los aranceles en universidades públicas más altos del mundo se encuentran en países con los aranceles conocidos como dual track, incluyendo Rusia y el resto de los países emergentes de la antigua Unión Soviética, además de otros países postcomunistas o postsocialistas de Europa del Este y Central y países en África del Este. Tales países aún entregan educación universitaria gratuita o con aranceles muy bajos (en general según lo dispuesto en sus constituciones) para aquellos postulantes que obtienen un puntaje suficientemente alto en rigurosos exámenes de admisión, a fin de aceptar en un determinado año solamente el número de estudiantes que los Estados pueden financiar con dichos aranceles tan bajos (o inexistentes), permitiendo que otros estudiantes considerados admisibles ingresen pagando aranceles muy altos que a veces cubren el costo completo de instrucción.

No obstante en Rusia, Rumania o Uganda no existe la pretensión de que el público obtenga en general todo el beneficio de la educación superior de estos estudiantes patrocinados por el Estado -así como tampoco está instalada la noción de que no existe ningún beneficio público derivado de la llamada opción pagada (fee paying track)-. El sistema se mantiene mediante una ley marco o una constitución que los gobiernos son reacios (o políticamente incapaces) de enmendar y 
por normas culturales que aprueban la recompensa de una educación superior de alto costo (para el Estado) para quienes hayan logrado el nivel académico más alto a la edad de ingresar a la universidad, aun cuando los estudiantes admitidos como patrocinados por el Estado provienen desproporcionadamente de familias de clase media y media alta con padres con educación universitaria. Pero si hay algo que confirman los abultados aranceles de los que pagan (fee-paying track) en las de otro modo universidades públicas en estos países, es la noción de los grandes beneficios privados derivados de la educación superior, siendo la educación superior gratuita o casi gratuita un artefacto no tanto de la creencia en el valor predominantemente público de la educación superior, sino de una ideología política resiliente acerca de que la educación superior debiera ser gratuita, aun cuando solo lo sea para unos pocos entre los más afortunados.

En síntesis, los aranceles son complejos y se deben analizar dentro del contexto de los costos cubiertos por los padres y los estudiantes, tanto para la instrucción como para la mantención, incluyendo el arancel y otros cobros obligatorios, las muchas variantes de aranceles (por ejemplo, el pago por adelantado, diferido, o dual track) y todas las formas de ayudas financieras. Considerados todos estos factores, el nivel de aranceles revela poco acerca de las visiones prevalecientes de los beneficios privados en contraposición con los beneficios sociales de la educación superior.

Malentendido frecuente 3: La educación superior pública gratuita (o de muy bajo costo) para profesiones esenciales tales como del área de la salud (médicos, odontólogos, enfermeras y otros profesionales de la salud), profesores, trabajadores sociales y otras profesiones, es un reconocimiento de la gran necesidad pública por estas profesiones y, por lo tanto, del gran valor social o público (en contraposición con lo privado) de su educación superior.

Esta es una variación del primer malentendido frecuente, asociada a un programa o a una profesión en particular, que constituiría una justificación de la educación superior gratuita o de muy bajo costo para todos, sobre la base de una afirmación de la primacía de los beneficios sociales en contraposición con los privados. Pero el 
hecho incuestionable de que todos necesitamos médicos (además de enfermeras y profesores y algunos dirían, incluso, banqueros y abogados) no hace que la educación médica (u otro tipo de educación profesional avanzada) sea un bien público en el sentido en que dicho término es utilizado por economistas para identificar bienes y servicios que no serán producidos en suficiente cantidad o calidad por el mercado privado por sí solo y que, por lo tanto, requerirán de un subsidio público (impuesto) para reducir su precio y aumentar su producción. Un verdadero bien público posee las características esenciales de no rivalidad, o sea que su consumo por parte de un individuo no reduce su disponibilidad para ser consumido por otros, y de la no exclusividad, es decir, que una vez producido cualquiera puede consumirlo o utilizarlo. Es en este sentido que la protección policial, la defensa nacional y la verdadera investigación básica se consideran bienes públicos que no serían provistos adecuadamente por el mercado privado y que, por lo tanto, deben ser subsidiados (de forma completa o parcial) por todos los ciudadanos mediante los impuestos.

Las mismas lógicas para el subsidio de cualquier tipo de educación superior se aplican de la misma forma para la educación y formación de médicos (o enfermeras o cualquier otra profesión de gran necesidad social). Se subsidia el alto costo de la educación médica a través de un arancel subsidiado o ayuda financiera subsidiada (o ambas), ya sea debido a que el costo muy alto de los aranceles sin subsidio no generaría suficientes médicos o porque podría no generar los médicos de la calidad que necesitamos (por ejemplo, como resultado de que los aranceles altos se excluye de la educación a demasiados individuos de gran capacidad potencial y, por lo tanto, del ejercicio de la profesión) o porque queremos dar la oportunidad para que cualquiera se convierta en médico y, por esa razón, debemos reducir el costo efectivo de la educación médica con fines de equidad social, algo para nada relacionado con el propósito de proveer profesionales en número y calidad suficiente. Cada una de estas lógicas es social y políticamente atractiva y explica por qué subsidiamos la educación médica. Pero son diferentes a una lógica a favor de aranceles muy bajos o inexistentes en facultades de medicina para todos sus estudiantes sobre la base de la noción (errónea) de que la medicina es un bien público. 
En otras palabras, el argumento a favor de la no existencia de aranceles en las facultades de medicina debido a que la medicina es un bien público y, por lo tanto, la educación médica debe ser gratuita sería sostenible únicamente si no existieran otras formas menos costosas y de menos inequitativas para que una sociedad obtuviese suficientes médicos calificados. Sin embargo sí existen. Los jóvenes ingresan a medicina por los enormes beneficios privados que obtienen, no solamente ingresos monetarios, sino también el prestigio y la satisfacción de superar los desafíos académicos e ingresar a una noble profesión. Estos jóvenes, al igual que sus padres, estarán dispuestos a pagar (o a solicitar un crédito) para tener tal oportunidad, y los ingresos generados por quienes paguen -sea por adelantado (principalmente los padres) o en forma diferida mediante el pago del crédito- es una fuente muy substancial de ingresos capaz de aportar a la capacidad o a la calidad de la facultad de medicina o de brindarles ayuda financiera a aquellos jóvenes para quienes los aranceles altos, incluso con las oportunidades de obtener crédito, resultan demasiado costosos.

Los subsidios del Estado, entonces, pueden ir a un subsidio parcial: dejando aranceles altos debido a los costos muy elevados de una educación médica de calidad, pero bajando los aranceles hasta niveles que sea posible pagar mediante el aporte de los padres y los créditos estudiantiles. Si los aranceles son demasiado altos para generar médicos en cantidad y calidad suficientes para ejercer en especialidades de alta demanda, pero bajos niveles de remuneración, tales como la medicina general o el ejercicio de la profesión en localidades remotas o de otro modo difíciles (tales como barrios urbanos con altos niveles de pobreza), entonces el Estado puede subsidiar selectivamente a quienes ejercen en estas subespecialidades o localidades mediante la condonación de porciones de la deuda por cada año que el médico (o el odontólogo o la enfermera) realmente ejerza esa especialidad en esa localidad. En otras palabras, si el objetivo de la política pública es entregar la mejor educación médica para el bien social común, es decir, un número suficiente de los médicos más cualificados, incluyendo quienes ejercerán en especialidades de menores remuneraciones además de ejercer en localidades remotas o difíciles, existen con toda seguridad formas mucho más costo-efectivas 
que la educación médica gratuita o de arancel muy bajo para todos los estudiantes de medicina.

Malentendido frecuente 4: La promoción de la educación terciaria entre individuos de bajos ingresos y otros marginados financieramente en la sociedad se realiza de mejor manera mediante la educación superior pública gratuita (o al menos de muy bajo costo) que mediante aranceles moderados más ayudas financieras.

La educación superior gratuita o de muy bajo costo -es decir, aquella en la cual los costos de instrucción de la educación superior son cubiertos exclusiva o casi exclusivamente por el contribuyentepodría por cierto tener más sentido que un arancel moderado más ayudas financieras para mantener la accesibilidad cuando prevalecen todas o la mayoría de las siguientes condiciones:

- La educación superior o posecundaria no es predominantemente una opción exclusiva para los hijos de las familias más privilegiadas.

- Los impuestos para apoyar la educación superior, particularmente en el margen de los aumentos tributarios, son relativamente costoefectivos y, al menos, relativamente progresivos, de manera que los impuestos adicionales requeridos para mantenerse al día con los costos crecientes no sean en sí mismos tan costosos de recaudar y no recaigan desproporcionadamente sobre las clases socioeconómicas media y baja (como los impuestos al consumo, los servicios básicos o los impuestos ocultos de la inflación inducida por déficit).

- Las normas culturales prevalecientes sostendrían que los aranceles -de ser cobrados- deberían ser pagados, principalmente, por los estudiantes más que por sus padres.

- Existen pocas universidades privadas dependientes de aranceles que sean académicamente respetables para sugerir en qué medida las universidades públicas gratuitas o de aranceles bajos se están alejando de la provisión de educación superior gratuita o de arancel bajo para todos.

- Los costos de oportunidad del inevitablemente creciente presupuesto del Estado para la educación superior -es decir, el siguiente 
mejor gasto público alternativo no realizado y que se podría haber ejecutado si parte del ingreso adicional requerido para la educación superior pudiera provenir de otras fuentes de ingresos distintos de los tributarios- generan un menor bien público que el beneficio logrado mediante el gasto de ingresos tributarios cada vez mayores en la educación superior. En otras palabras, existen pocas grandes necesidades públicas que no estén siendo satisfechas debido a la falta de recursos públicos y que se podrían financiar transfiriendo costos del arancel desde el Estado a los padres y a los estudiantes.

Las condiciones anteriores generalmente se cumplen en los países nórdicos donde pareciera no existir una ventaja significativa de la política pública asociada con la imposición de aranceles incluso moderados, los cuales por cierto serían de todos modos resistidos ferozmente por los padres y los estudiantes por igual (aun cuando los padres claramente podrían y probablemente también estarían dispuestos a pagar un arancel modesto si fuese necesario). Al mismo tiempo, en la mayoría de los países del mundo y especialmente en los países de ingresos medios y bajos:

- La educación superior es desproporcionadamente una opción de las clases media, media-alta y alta.

- Aumentar los ingresos del Estado no es particularmente progresivo (especialmente cuando se logra a través de la confiscación inflacionaria del poder adquisitivo mediante el gasto deficitario), ni tampoco son la mayoría de los impuestos costo-efectivos en el margen, es decir, los impuestos tienden a ser no solamente regresivos, sino también difíciles y costosos de recaudar.

- Los padres sí creen que, de cobrarse aranceles, les corresponde a ellos pagarlos, si es que cuentan con la capacidad financiera para hacerlo, lo cual hace que el cobro de aranceles y la ayuda financiera de acuerdo a situación socio-económica sean otras formas de lograr un poco de la socialmente deseable redistribución del ingreso.

- La educación superior privada con pago de aranceles es frecuente, creciente, y generalmente respetable (a menudo en Estados Unidos este tipo de educación cuenta con mayor prestigio que las instituciones públicas de aranceles mucho menores). 
- La lista de necesidades públicas social y políticamente convincentes, pero carentes de financiamiento (por ejemplo, educación básica y media, salud pública, formidable infraestructura pública) es larga y formidable, lo cual sugiere que asignar fondos públicos adicionales todos los años a la educación superior tiene un costo de oportunidad muy alto.

Muchas de estas condiciones se cumplen en países con una disparidad tan amplia como Estados Unidos, China, Rusia, Brasil, Kenia, Burkina Faso y la gran mayoría de países de Europa continental en cuanto, por ejemplo, a la riqueza per cápita, la calidad (no obstante cómo se mida) de los colleges y de las universidades, las tasas de participación en la educación superior, además de la mayoría de las normas sociales y culturales. Estados Unidos y China (al igual que Japón y Canadá) ya cuentan con aranceles significativos en sus instituciones públicas de educación superior - en el rango de 20\% a 40\% de los costos de la instrucción. La mayoría de los países de Europa continental, los países en transición de la antigua Unión Soviética, la mayoría de África y la mayoría de América Latina, sin embargo, cuentan con aranceles muy bajos o inexistentes en sus instituciones públicas de educación superior (o al menos en las opciones apoyadas por el Estado en los países con dual track). En tales casos -y especialmente cuando subir los impuestos resulta difícil y altamente regresivo, cuando los estudiantes de colleges y universidades provienen desproporcionadamente de las clases más pudientes y afluentes, cuando existen sectores privados crecientes que demuestran la capacidad y la disposición de muchas familias para pagar un arancel moderado y donde existe la ayuda financiera- se puede afirmar el fracaso del Estado en imponer un arancel al menos moderado perdiendo un ingreso que de otro modo pudiera haber mejorado la calidad, capacidad, o ayuda financiera de la educación superior.

Malentendido frecuente 5: Los aranceles en el sector público constituyen la principal barrera financiera para la accesibilidad y mayor participación en la educación superior.

Si bien los aranceles son una política controversial de financiamiento de la educación superior, mientras que estos se 
encuentren en el rango moderado ( $15 \%$ a $25 \%$ del costo de la instrucción) y mientras que la mayoría de los estudiantes alrededor del mundo sean incapaces de asistir tiempo completo y aún vivan en las casas de sus padres, los costos de vida o de mantenimiento son lejos la mayor barrera financiera que ellos y sus familias deben de algún modo superar. Más aún, además de la alimentación y el alojamiento están los costos asociados a los textos, los costos de los exámenes y de inscripción (no vinculados con los aranceles), computadores y otros gastos relacionados con la educación superior, sumado a todos los otros costos de la vida como vestimenta, entretención, transporte, teléfonos celulares y similares. Esto no niega el hecho que el financiamiento pueda representar una barrera crítica para la participación en la educación superior de personas jóvenes de familias de bajos ingresos. No obstante, en general existen otras formas de reducir estas barreras, mucho más costo-efectivas que los aranceles muy bajos o inexistentes: específicamente, la ayuda financiera en base a situación socio-económica o focalizada, junto con aranceles moderados para aquellos padres y estudiantes que pueden y están dispuestos a pagar una parte de los costos subyacentes de la instrucción.

Malentendido frecuente 6: La política e ideológicamente cuestionada imposición de aranceles (o su aumento) para los colleges y universidades públicas no es más que una opción de los gobiernos para no aumentar los impuestos como alternativa al "impuesto efectivo" del arancel.

Vale la pena replantear una lógica clave que apoya el hecho de compartir los costos en muchos países: la carga de impuestos y déficits adicionales en la mayoría de los países son al menos, proporcionales y probablemente regresivos, por más que los gobiernos deseen o afirmen lo contrario -es decir, que estos recaen sobre todos los ciudadanos, inclusive sobre los pobres, en vez de recaer principal y progresivamente sobre los más pudientes - y quienes se benefician de los aranceles bajos o inexistentes tienden a pertenecer desproporcionadamente a las clases medias, media-alta y alta. Sin embargo, cabe establecer dos puntos adicionales, también sugeridos anteriormente. Primero, los costos de oportunidad de asignar recursos públicos adicionales a la educación superior, particularmente en países de ingresos medios y bajos con 
sus enormes rezagos en necesidades no financiadas en sectores tales como la educación básica y media, vivienda, infraestructura pública, o sanidad y restauración ambiental, sugiere con casi total certeza que la educación superior en la mayoría de los países (incluyendo los más ricos) no se encuentra en el primer lugar para recibir tales fondos. Segundo, no está para nada claro cuántos ingresos adicionales por recaudación tributaria o mediante créditos sean posibles de lograr, especialmente en los países de ingresos medios y bajos y que ya se encuentran en el límite o cerca del límite de los impuestos que se pueden agregar en forma costo-efectiva y que están, además, en el límite o cerca del límite de su capacidad de endeudamiento. En síntesis, en muchos países la imposición de impuestos adicionales es improbable, pero aún si se pudiera lograr, es poco probable que la educación superior sea la beneficiaria.

Malentendido frecuente 7: La necesidad de todos los países de ser competitivos en la cada vez más globalizada economía mundial -y de que los jóvenes obtengan empleos decentemente remunerados- requiere que más jóvenes obtengan al menos una licenciatura.

La evidencia es bastante concluyente de que los ingresos aumentan con el nivel de educación e indudablemente continuarán haciéndolo. Pero la evidencia es mixta y compleja cuando se trata de la necesidad de que todos o incluso que más jóvenes obtengan una licenciatura o incluso títulos técnico-profesionales. Los egresados de colleges y universidades cesantes o subempleados constituyen un fenómeno en casi todos los países. Puede que los restaurantes y bares en Estados Unidos prefieran contratar egresados de los colleges (25\% de los barman son egresados de colleges), pero la Oficina de Estadísticas del Trabajo en Estados Unidos no clasifica el trabajo de barman como un empleo que requiera de un título de un college (Harrington y Sum, 2010).

El análisis de Harrington y Sum de los datos referidos al mercado del trabajo en Estados Unidos mostró que cerca del 16\% de los recién egresados de colleges trabajaban en el sector de ventas minoristas (retail), el 10\% como barman y meseros y el 6\% como 
secretarias o personal de oficina -y ninguno de dichos trabajos se encuentra clasificado como un empleo que requiere un nivel de educación más allá de la enseñanza media. Puede que la noción de que necesitamos más egresados con un nivel de por lo menos una licenciatura se deba a que confundimos los hechos que: a) la mayoría de los buenos empleos requieren de títulos otorgados por colleges o universidades; b) que algunas de las ocupaciones de más rápido crecimiento y de tendencia a escasear alrededor del mundo requieren no solamente títulos avanzados, sino que necesitan más de tales graduados; con nuestra creencia legítima de que c) todos los jóvenes debieran tener la oportunidad de lograr el más alto nivel de conocimiento y empleos altamente remunerados $-\mathrm{y}$, por lo tanto, que muchos aspirantes requerirán adquirir niveles altos de educación para tener dicha oportunidad, aun cuando muchos tendrán que retornar a una ocupación que no requiera del título cuando no tengan éxito en lograr los cargos u ocupaciones a los cuales aspiraban.

Por supuesto que los beneficios tanto públicos como privados de la educación superior van mucho más allá de obtener un empleo particular y no hay nada inherentemente equivocado con tener un nivel de egresados de colleges o universitarios subempleados o cesantes, si es que eso se puede costear y si el nivel de cesantía entre egresados de colleges y universitarios no tuviese otras consecuencias económica o socialmente indeseables. Pero sostener que todos o incluso la mayoría de los empleos requieren contar con un nivel de licenciatura, incluso en los países altamente industrializados, ahora o incluso en el futuro inmediato, claramente es un error.

Malentendido frecuente 8: La elasticidad precio de los aranceles de la educación superior -es decir, el efecto en (o la caída de) la matrícula como resultado de un aumento en los aranceles- es considerable y por lo tanto resulta esencial al diseño de una buena política pública para el financiamiento de la educación superior (o sea, equilibrar la necesidad de mayores ingresos con la necesidad de mantener una amplia participación y accesibilidad).

El efecto de cambios en los aranceles, ayudas financieras, o en la composición de la ayuda financiera (por ejemplo, entre becas o 
créditos, o entre tasas de interés altas o bajas) en el comportamiento de la matrícula es crítico para el diseño apropiado de la política pública acerca de los aranceles y otros cobros, criterios de elegibilidad, generosidad y composición de la ayuda financiera. La elasticidad precio de los aranceles ha sido tema de investigación considerable en Estados Unidos, el Reino Unido y otros países de la Organización para la Cooperación y el Desarrollo Económicos, OCDE. La investigación más refinada ha estudiado el efecto de cambios en los aranceles netos (luego de la ayuda financiera). Sin embargo, es prácticamente imposible realizar un experimento verdadero tipo modelo médico donde conjuntos de postulantes seleccionados aleatoriamente reciben diferentes paquetes de aranceles y ayuda financiera, sin posibilidad de realizar revisiones ex post $\mathrm{u}$ ofertas alternativas de aranceles y ayuda financiera. Por lo tanto, la investigación debe ser cuasi experimental, en la que los cambios en matrícula se estudien mediante análisis de regresión para buscar una explicación posible de los cambios en los aranceles, o investigación por encuesta, en la que se pregunta a un postulante o actual estudiante qué haría frente a cambios hipotéticos en los aranceles.

Ese tipo de investigación generalmente muestra que los cambios en los aranceles para la mayoría de los estudiantes tiene poco efecto; pero generalmente sí muestra efectos sobre los estudiantes provenientes de familias de menor nivel socioeconómico, quienes podrían tener escasas o nulas posibilidades de absorber incluso un leve aumento de los aranceles, o en quienes podrían estar más ambivalentes desde el inicio sobre los rigores académicos de un college o universidad (Johnstone y Marcucci, 2010b). Simultáneamente, al menos en Estados Unidos y otros países y regiones donde existen alternativas de educación posteriores a la enseñanza media entre las cuales los estudiantes (y generalmente también sus familias) pueden escoger, el efecto de un aumento en los aranceles y/o una reducción o cambio en la ayuda financiera no significaría la decisión de no asistir o de desertar, sino la decisión de tomar un empleo a tiempo parcial o trabajar más horas, u obtener más crédito, o (particularmente en Estados Unidos) cambiarse a una institución de menor precio o mudarse de vuelta a la casa de los padres. 
De este modo, los intereses académicos y de la política pública en la elasticidad precio de los aranceles no constituyen exactamente un malentendido, ni tampoco es incorrecto o irrelevante. Todo lo contrario, el efecto de los cambios en los aranceles y ayuda financiera sobre el comportamiento de la matrícula es de gran importancia. Pero la mayoría de los hallazgos de investigación citados más a menudo por ejemplo, que cada aumento en $\$ 100$ del arancel llevará a un cierto porcentaje de caída en la matrícula agregada- resultan contrarios a todas las observaciones, y no consideran comportamientos relevantes además de la decisión de matricularse o no matricularse, que ofrecen poca orientación para las políticas públicas sobre los aranceles y ayuda financiera apropiados, e incluso podrían ofrecer proyecciones incorrectas, y en todo caso incompletas, del probable comportamiento de los estudiantes.

Malentendido frecuente 9: Si un país no puede seguir costeando la educación superior pública con un arancel bajo o inexistente (tal como al parecer cada vez más países deciden), entonces los países deberían mantener la educación superior gratuita al momento de la matrícula para un primer título y diferir el pago de aranceles hasta después de la graduación (preferiblemente, como en Inglaterra o Australia, disponiendo el pago a través de un requerimiento a los empleadores para que se retenga un porcentaje de las remuneraciones mensuales, similar a los descuentos por el seguro de salud, el fondo de pensiones o la retención del impuesto a la renta, hasta pagar el crédito en su totalidad)

Los planes australianos e ingleses de aranceles diferidos a ser pagados como crédito contingente a los ingresos, poseen dos características distintivas: ambos con proponentes fuertes, especialmente al ser tomados en conjunto, pero también cada uno con ciertas desventajas. La primera y principal característica del plan en Inglaterra es la propuesta de que la educación superior debiera ser gratuita al momento de la matrícula, aunque puede existir un arancel siempre y cuando su pago sea diferido hasta el momento en que se egresa (Barr y Crawford, 2004). Un arancel que es gratuito al momento de la matrícula y que luego es pagado por el estudiante como un crédito al egresar, resulta atractivo para muchos estudiantes porque 
libera a los padres de la obligación de pagar los aranceles y trata a todos los estudiantes como adultos financieramente independientes (si bien generalmente insolventes). El inconveniente de esta supuesta ventaja es que transfiere a los estudiantes una carga financiera que en la mayoría de los países no-nórdicos (y en el Reino Unido desde 1997 a 2006) es (o era) considerada una obligación correspondiente a los padres -al menos para aquellos dispuestos a pagar- (adicionales a los costos de vida que los estudiantes también puedan solventar). Un problema especial para los estudiantes de bajos ingresos es que cualquier beca o reducción del arancel que está (o estaba) determinada por los bajos ingresos de la familia ya no es aplicable. Así, cuando Inglaterra cambió en el año 2006 el cobro de aranceles al momento de la matrícula pagados por familias de clase media, media-alta y alta, por arancel diferido pagado por todos los estudiantes; los ganadores por supuesto fueron los padres ya que no se esperaba pago por parte de ellos, y los perdedores fueron los estudiantes, especialmente los estudiantes de familias de ingresos bajos, quienes (o cuyos padres) previamente no habían tenido que pagar ningún arancel.

Malentendido frecuente 10: Si un país es persuadido que los aranceles en el sector público son financieramente necesarios (sea al momento de la matrícula o diferidos) y que se les deben ofrecer créditos a los estudiantes (sea para cubrir los aranceles, el costo de mantención, o ambos), estos créditos deberían ser pagados como porcentaje de los ingresos futuros y no como cuotas fijas de pagos utilizado en un crédito hipotecario o de consumo convencional.

Durante los últimos cincuenta años, los analistas de políticas públicas, los políticos, estudiantes y muchos economistas han estado fascinados con la idea de que los créditos estudiantiles se pueden pagar no en base a un calendario fijo de pagos, sino como una obligación a pagar un cierto porcentaje de los ingresos hasta saldar el monto de la deuda más los intereses, o hasta -para quienes ganan menos- hayan pasado una cierta cantidad de años pagando dicho porcentaje de los ingresos, sin haber necesariamente liquidado el total de la deuda pero en ese momento la deuda restante quedaría cancelada. Los economistas tienden a estar particularmente intrigados por la forma pura, en la cual el excedente del interés pagado por las personas que 
más ganan efectivamente cubre las insuficiencias de los que ganan menos, convirtiendo al crédito estudiantil en una forma de equidad, en la cual los estudiantes son vistos como quienes venden acciones de sus ganancias futuras a cambio del capital que necesitan para invertir en su educación. El alto riesgo del crédito estudiantil disponible de manera generalizada, el problema de la selección adversa (mediante la cual los estudiantes que planean una carrera de bajos ingresos, tal como un apostolado o el servicio público, se apresurarán a participar; mientras que quienes creen que lograrán ingresos altos tenderán a no participar), y la dificultad de capitalizar o asegurar pagarés de créditos contingentes han limitado la adopción de créditos estudiantiles contingentes al ingreso, con la excepción de los créditos otorgados por el Estado. Los casos más notorios son los modelos de Australia e Inglaterra, que combinan las supuestas ventajas de los aranceles diferidos (por ejemplo, educación superior gratuita al momento de la matrícula) con las supuestas ventajas para los estudiantes de la obligación de pago del crédito contingente al ingreso. (La presunta ventaja se extiende también a los políticos, quienes generalmente desean complacer a los estudiantes, especialmente cuando se trata de aventurarse en las aguas políticamente traicioneras del cobro de aranceles para la educación superior.)

No obstante, si bien puede que se crea que los créditos con obligación de pago contingente al ingreso son muy superiores a los créditos convencionales sujetos a calendarios fijos de pago es importante señalar, en primer lugar, que la mayoría de los estudiantes pagará exactamente el mismo monto del crédito -medido en términos verdaderos del interés simple o el valor presente descontado de los pagos- según el calendario de pago contingente al ingreso, que el que pagarían en el caso de un crédito convencional equivalente, o tipo hipotecario, sujeto a un calendario de pagos fijos. Esto se debe a que un crédito resulta ser de menor costo solamente en la medida en que sea pagado a una tasa de interés menor y no hay nada en un calendario de pago contingente al ingreso que lo haga más subsidiado, o de menor costo que un crédito convencional, al menos para la mayoría de los deudores, aunque los pagos por cierto pueden resultar más manejables, siempre y cuando se suponga que un porcentaje constante del ingreso es más manejable que un calendario de pagos fijos y conocido. 
Además, debido a que prácticamente todos los esquemas de créditos contingentes al ingreso tienen un período máximo de liquidación de la deuda, después del cual el monto remanente adeudado por los deudores de bajos ingresos no han sido capaces de saldar completamente su deuda será condonado, la generosidad de un esquema de crédito contingente al ingreso dependerá del porcentaje de los ingresos que deberán pagarse (normalmente en forma mensual) y del número de años que se pueda exigir que un deudor continúe con el pago. Un alto porcentaje de ingresos utilizado para estipular el pago mensual junto con un largo período máximo de pago constituiría un crédito poco generoso, lo que significa que un deudor tendría que ser bastante indigente durante su vida laboral para poder gatillar la condonación de la deuda remanente. Inversamente, un contrato de pago con un porcentaje bajo del ingreso para los pagos mensuales y un período de pago corto probablemente signifique que muchos deudores podrían llegar al final de su período máximo de pago con una deuda remanente a ser condonada. El punto es que se puede reducir el costo de cualquier obligación a pagar -ya sea sujeta a pagos fijos o a pago contingente al ingreso- mediante una tasa de interés más baja (por ejemplo, con un mayor subsidio) y cualquier esquema de repago se puede hacer más manejable al extender el período de pago y permitir fácilmente un refinanciamiento, prórroga o indulgencia en caso de cesantía o de bajos ingresos. En síntesis, algunos defensores del formato del pago de la deuda contingente al ingreso presentan dicho formato como la mejor opción para todos los estudiantes. Pero para ser más precisos, el formato resulta claramente mejor únicamente para algunos estudiantes -el grado de lo que se considera mejor y la proporción de deudores para quienes el formato es efectivamente mejor dependerá de los elementos de subsidio estatal integrados al esquema específico de crédito contingente al ingreso- no, al final, muy distinto de los subsidios que se pueden incluir en otras formas de pago de créditos.

Tampoco es necesariamente mejor para el prestamista el pago contingente al ingreso. La contingencia al ingreso en los modelos australianos e ingleses a veces se equipara erróneamente con la recaudación de pagos a través del empleador por planilla de sueldos, como ocurre con la retención del impuesto a la renta o las cotizaciones 
para el fondo de pensiones. Sin embargo, un Estado capaz de obligar a los empleadores a recaudar el pago de los créditos contingentes al ingreso de sus empleados puede, supuestamente, hacer lo mismo para los créditos estudiantiles del tipo convencional. Y podría incluso existir un inconveniente asociado a tener créditos estudiantiles cuyos pagos sean recaudados por el empleador. Por ejemplo, la opción de pago contingente al ingreso que ha existido durante muchos años en Estados Unidos no es recaudado por los empleadores (ni es tampoco particularmente generoso), ya que el Servicio de Impuestos Internos de Estados Unidos no desea poner en riesgo su alto nivel de cumplimiento tributario voluntario, adjuntando una tarea que no está relacionada con la recaudación de impuestos, las normas y reglamentos sobre la retención del impuesto a la renta. No se trata de menospreciar un esquema de crédito que depende de los empleadores para la recaudación (aunque es difícil de imponer esa recaudación a los trabajadores independientes y a quienes trabajan fuera del país). El punto solamente tiene como objetivo desasociar la recaudación por parte de los empleadores de la contingencia al ingreso.

Un inconveniente de los créditos contingentes al ingreso para el prestamista (el Estado en Inglaterra, Australia y todos los demás países que actualmente ofrecen créditos contingentes al ingreso para los estudiantes) radica en que el prestamista (el Estado) obtiene activos en forma de contratos o pagarés mediante los cuales el estudiante deudor se compromete a entregar una cierta parte de sus ingresos en calidad de pago hasta saldar la deuda a una cierta tasa de interés o hasta que haya transcurrido una cierta cantidad de años. No obstante, a diferencia de los pagarés de créditos convencionales con pagos fijos, los cuales poseen un valor de mercado y pueden ser vendidos en un mercado secundario o asegurados para reunir capital en los mercados de capital privado; las obligaciones contingentes al ingreso no tienen, al menos hasta principios del año 2012, prácticamente ningún valor de mercado. El Estado puede contabilizarlos en sus estados financieros como activos a un valor bastante poco determinado. Pero si la idea del arancel diferido era en primer lugar ofrecer una fuente adicional no gubernamental de ingreso para los colleges y universidades públicos de un país, poco ayuda que los aranceles deban ser financiados con el presupuesto operacional del Estado y deban competir con todos 
los otros gastos públicos. Inglaterra y Australia pueden tomar como préstamo estos fondos y agregarlos a su deuda, tranquilos quizás al saber que existen ciertos activos compensatorios en sus estados financieros, aun cuando dichos activos sean de un valor incierto y de poco valor en el mercado mundial de capitales. Pero para un país de ingreso bajo que esté fuertemente restringido a causa de su nivel de deuda y de todas las demás exigencias puestas sobre el presupuesto operacional del Estado, los activos de las obligaciones por aranceles diferidos pueden resultar de muy poca ayuda.

Finalmente, los créditos estudiantiles de la variedad contingente al ingreso son claramente más aceptables para los estudiantes y políticos y también para muchos economistas y analistas de políticas públicas. Y existen claras ventajas, aunque algunas de ellas, tales como la recaudación por parte de los empleadores mediante descuentos en la planilla de remuneraciones, no sean una característica exclusiva de los créditos de contingencia al ingreso, y existen otras formas sin llegar a la contingencia del ingreso para proteger a los deudores de bajos ingresos de un nivel inmanejable de deuda. De este modo, mi refutación a los defensores de los créditos contingentes al ingreso, que a menudo se muestran demasiado entusiastas respecto de los mismos, no radica en que dichos defensores estén totalmente equivocados, o que este tipo de crédito sea necesariamente malo, sino que el concepto del crédito estudiantil contingente al ingreso es frecuentemente malentendido y además sobrevendido.

Malentendido frecuente 11: Si un país ya no puede costear gratuidad o aranceles muy bajos para la educación superior pública (por ejemplo, tal como lo han decidido Rusia y otros países de la antigua Unión Soviética, además de los anteriores países comunistas de Europa Central y del Este y muchos de los países de África subsahariana), es aún preferible ofrecer educación superior gratuita o con un arancel muy bajo para la mayor cantidad de personas que resulte financieramente posible, comenzando con los de mayor mérito académico.

El debate sobre una serie de malentendidos ha planteado las llamadas políticas de aranceles dual track en muchos países en 
transición y en otros donde la educación superior gratuita o de arancel muy bajo es un imperativo político, pero donde los ingresos públicos son insuficientes para la política pública. El dual track ofrece aranceles gratuitos o muy bajos para los estudiantes más capaces académicamente, mientras que admite un número sustantivamente mayor (hasta el 80\% en la Universidad de Makerere en Uganda) de estudiantes supuestamente calificados que deben pagar un arancel muy alto. Los países ajustan el punto de corte del examen de admisión hacia arriba o hacia abajo (generalmente hacia arriba) en base a la cantidad de estudiantes de primer año que el Estado puede patrocinar con gratuidad o aranceles bajos; y luego se admite un número suficiente de otros estudiantes con un arancel mucho mayor, patrocinado privadamente, a fin de ampliar la capacidad de la universidad a un costo bajo o sin costo adicional alguno (y quizás a veces con una utilidad).

Los problemas de las políticas arancelarias dual track son dos. Primero, se considera que generalmente exacerban las inequidades existentes en prácticamente todos los sistemas de educación superior: la representatividad desproporcionada de estudiantes de familias ya privilegiadas. Es cierto que al ofrecer educación superior a un arancel muy bajo o inexistente para los más capaces académicamente, tales políticas son capaces de acomodar a los estudiantes más pobres -siempre y cuando estos hayan sobresalido académicamente en la enseñanza media. Al mismo tiempo, el logro académico y la ambición se construyen, al menos en cierta medida, social y culturalmente. Los hijos e hijas de familias privilegiadas poseen las ventajas de asistir a mejores establecimientos de educación media, tienen pares más ambiciosos en lo académico y cuentan con el capital cultural inherente a los hogares con padres educados, libros, etcétera. Una política dual track de aranceles, o de aranceles paralelos, se encarga de los pobres más capaces en lo académico. Al mismo tiempo, los hijos e hijas de familias privilegiadas, tanto los más capaces como los menos capaces académicamente, siempre estarán resguardados (si no en las universidades más prestigiosas, entonces en los colleges y universidades que están siempre accesibles y que igual conllevan un retorno privado). Son los estudiantes de las familias de menores ingresos, académicamente capaces y ambiciosos aunque no lo 
suficiente para acceder a las opciones patrocinadas por el Estado, a quienes se les niega la oportunidad de una educación superior, porque la familia no puede pagar los altos aranceles de colleges o universidades privadas o las opciones con pago de arancel en las instituciones públicas.

El otro problema de la política dual track es que los aranceles son demasiado bajos, inferiores a lo necesario, y por lo tanto, renuncian a ingresos adicionales en la opción patrocinada por el Estado, y demasiado altos -lo suficientemente para negar oportunidades a los estudiantes de familias de bajos ingresos en la opción que paga aranceles (fee-paying track). Las políticas de aranceles dual track están firmemente arraigadas en culturas políticas e ideológicas y son resisten al cambio. Sin embargo, a medida que aumentan los postulantes calificados para la universidad, y la austeridad financiera continúa limitando los estudiantes que se aceptan en las opciones patrocinadas por el Estado, y las proporciones de estudiantes en las opciones que pagan aranceles también continúa creciendo; podría llegar un momento en que la cantidad de estudiantes en las opciones patrocinadas por el Estado sea lo suficientemente baja como para parecerse a un conjunto de becas generosas basadas en el mérito. En ese momento, la muy criticada inequidad de las políticas de aranceles en dual track son similares a, y por cierto no peores que, el muy criticado (al menos por la mayoría de los académicos y especialistas en políticas públicas) aumento en las becas por mérito en universidades públicas de Estados Unidos - también producto de la política y de una cultura que busca recompensar el mérito más que asistir a quienes se consideran menos meritorios académicamente, pero para quienes la ayuda o el arancel bajo podría realmente hacer una diferencia.

Malentendido frecuente 12: Si los países ya no pueden costear una educación superior pública gratuita o de muy bajo arancel y deben aumentar los aranceles y otros cobros -por supuesto que complementado con programas de ayudas financieras para mantener la accesibilidad-son mejores para mantener el acceso las becas que los créditos porque: a) demasiados estudiantes, especialmente los de familias de menores ingresos, son culturalmente aversos a las deudas y simplemente no se endeudarán, y así se les seguirá 
negando el acceso a la educación superior; y b) muchos programas de créditos estudiantiles alrededor del mundo han fracasado financieramente debido al alto incumplimiento y costo del servicio de la deuda.

Existen advertencias importantes relacionadas con esta postura. Una de ellas es que por cierto existen algunas culturas que tienen aversión a las deudas, y tal vez en especial para la educación superior de las mujeres. Simultáneamente, al igual que lo ocurrido con el estudio de la elasticidad precio de los aranceles, la investigación de la aversión a la deuda potencial de los estudiantes es difícil y frecuentemente no concluyente. Los estudiantes o potenciales estudiantes pueden ser encuestados sobre su probable comportamiento o sentimientos en situaciones hipotéticas de necesidad de dinero adicional, preguntándoles cómo se sienten en relación con el endeudamiento para educación superior, o a las circunstancias en las cuales podrían endeudarse en contraposición con algún otro comportamiento, tales como abandonar los planes de matricularse en un college o universidad, desertar, o intentar arreglárselas con menos recursos para sus gastos de mantención a tal punto de perjudicar su salud. Sin embargo, los estudiantes bien podrían creer que cualquier respuesta, fuera de la más dramática e inaceptable para los formuladores de política pública -como amenazar con desertar o con abandonar totalmente sus planes de obtener una educación universitaria- podría constituir una invitación para que los formuladores de políticas sigan adelante con los planes del gobierno de imponer un aumento del arancel o cambiar la oferta de becas o subsidios por créditos.

Por supuesto que la aversión al endeudamiento puede, de hecho, ser lo suficientemente seria como para denegar a algunos estudiantes la opción de un crédito, en especial a las mujeres jóvenes en algunos contextos culturales; lo cual puede significar para ellas una virtual negación de la oportunidad de acceder a la educación superior. Al mismo tiempo (y con la intención de ser deliberadamente provocativo) la educación superior como tal en algunos países y culturas alguna vez fue considerada inapropiada para las hijas, pero afortunadamente esto ha cambiado de forma significativa. De 
hecho, aunque algunas culturas son aún aversas a ciertos aspectos de la modernidad tales como citas casuales, la mayoría ha aceptado, por ejemplo, las tarjetas de crédito, los teléfonos celulares e incluso la educación profesional avanzada en administración y negocios o derecho. Actualmente, la disposición a asumir una deuda para las oportunidades que se abren mediante la educación superior puede ser otro aspecto de la modernidad que todavía puede ser difícil de aceptar para algunas familias. El tema, entonces, podría ser el grado al cual se le puede pedir al contribuyente adaptar su aversión a la deuda educacional culturalmente persistente mediante becas a un costo cada vez mayor, cubierto por el Estado o con aranceles bajos para todos, en lugar de créditos.

El otro germen de verdad en la afirmación de que los esquemas de créditos estudiantiles "simplemente no funcionan" es que por cierto muchos han fracasado financieramente. Así, el mundo en desarrollo está plagado de programas de crédito fracasados. Shen y Ziderman (2007) han mostrado muchas instancias de programas de crédito estudiantiles con valor presente descontado de los flujos razonables de pago del crédito mucho menor de lo prometido cuando el programa de crédito fue inaugurado como paso en la dirección de compartir los costos -y algunos pocos malos ejemplos en que el valor presente del pago es tan bajo que el Estado habría ahorrado recursos si desde el inicio le hubiera entregado el dinero a los estudiantes en forma de becas en vez de créditos, ahorrándose además el costo de intentar recuperar los fondos.

Sin embargo, estos ejemplos (y existen varios) rápidamente revelan una cantidad de razones por las cuales los esquemas de créditos estudiantiles fracasan, además de cómo los fracasos se pueden aminorar o prevenir (Johnstone y Marcucci 2010a, 2010b). En la mayoría de los casos, las tasas de interés se fijaron por debajo del costo del dinero, lo cual significa que el programa hubiera fracasado financieramente aún si todos los deudores hubieran pagado. Además, los esquemas de crédito estudiantil frecuentemente se han implementado sin instrucciones u orientaciones para los estudiantes sobre el significado de la deuda y las consecuencias del no pago. Tanto es así que muchos gobiernos, temiendo la reacción de los estudiantes 
en contra de cualquier cosa que se asemeje al costo compartido, ni siquiera reconocieron que un esquema nuevo, como un arancel diferido, en realidad significaba un arancel más un crédito. En tales planes en general no hubo traspaso de dinero a los estudiantes, sino que simplemente se anotó una deuda con la matrícula -una deuda que los estudiantes, al momento de egresar, bien podrían haber olvidado o para la cual de todos modos no habrían estado preparados de asumir. Con frecuencia los gobiernos establecían esquemas de crédito sin una preparación técnica o legal para el servicio de la deuda, haciendo que la recaudación fuera poco probable incluso si los deudores tenían inicialmente la intención de pagar. En otras palabras, nuestros estudios de créditos estudiantiles fracasados dejan de manifiesto por qué tantos programas han fallado a tal punto que creemos que los créditos estudiantiles sí pueden funcionar: con suficiente capitalización inicial, la disposición del gobierno de absorber una alta proporción del riesgo inherente, una tasa de interés apropiada, la participación del college o universidad, además de un enfoque profesional adecuado para el servicio y cobro de la deuda (Johnstone y Marcucci 2010a, 2010b).

Malentendido frecuente 13: Si los países no pueden costear educación superior pública gratuita o de muy bajo arancel y necesitan inaugurar una política de aranceles y otros cobros (complementados con ayudas financieras para mantener la accesibilidad), estos aranceles deberían, al menos, aumentarse lo menos y con la menor frecuencia posible.

El punto de transferir algunos de los costos de la educación superior desde el Estado a los padres y estudiantes es que los costos de la trayectoria educacional, impulsados tanto por los costos crecientes por estudiante como por la matrícula progresiva, excede en la mayoría de los países la trayectoria de ingresos fiscales disponibles (por ejemplo, impuestos). El resultado de estas trayectorias divergentes, nuevamente en casi todos los países, es un aumento anual en la austeridad institucional, que conduce a la restricción de la capacidad y a una menor calidad. El caso es claramente que los aranceles se encuentran disputados políticamente y que pueden imponer serias dificultades a muchas familias y estudiantes -a tal punto de limitar o, al menos, afectar su acceso a la educación superior. No obstante, 
si la razón detrás de los aranceles es la incapacidad del Estado de mantenerse al día con el alza acelerada de los costos y las necesidades de recursos, y si estos ambos aumentan prácticamente año tras año (especialmente con la creciente demanda de matrícula) y si se realizan las provisiones para mantener el acceso mediante becas por nivel socio-económico y créditos, entonces cualquier congelamiento de los aranceles significa que la contribución del Estado debe aumentar aún más -para compensar el hecho de que el aporte de los padres y estudiantes no se incrementa para nada- o los colleges y universidades deberán asumir recortes aún mayores. Incluso más, cuando el Estado, habiendo inaugurado una política de aranceles moderados posteriormente los congela -probablemente en vista de que prácticamente todos los demás gastos y precios continúan al alzael gobierno está enviando una señal poco clara a los estudiantes: su educación superior, que desde el inicio estaba a un precio altamente subsidiado, y los costos subyacentes que continúan subiendo año tras año, debieran de algún modo ser inmunes a la inflación que el estudiante ve en todas partes.

Una política preferible consistiría en que el gobierno determinara una proporción adecuada (al menos aproximada) de los costos de la educación a ser cubierta por los padres y los estudiantes -cuyo aporte se verá afectado necesariamente, por ejemplo, por la historia, la capacidad económica y la política actual de seguir aumentando los impuestos, la existencia de un sector privado que depende de un arancel, y la fortaleza del sistema de ayudas financieras- y luego mantuviera esa proporción, lo que probablemente implique pequeños aumentos del arancel durante la mayoría de los años. Pero una política consistente en mantener una participación adecuada de parte de la familia también sirve para centrarse políticamente en la necesidad de sostener la proporción del Estado la cual, al igual que la proporción de la familia, se espera que se mantenga -y así también que aumentedurante la mayoría de los años junto con los costos subyacentes crecientes de la educación y la matrícula.

Malentendido frecuente 14: Por último, si se considera necesario contar con un programa de crédito estudiantil, este se debiera diseñar para que sea financieramente autosustentable: es 
decir, que el pago posterior sea suficiente para cubrir los nuevos créditos requeridos.

Este es un tema recurrente de las propuestas nuevas de programas de créditos estudiantiles, sin base en la teoría ni en la práctica. Es extremadamente improbable que el pago de créditos anteriores sea suficiente para constituir la única fuente utilizada para cubrir el otorgamiento de nuevos créditos, debido tanto a las pérdidas inevitables como resultado de incumplimientos y subsidios integrados (los cuales se pueden reducir mediante una tasa de interés más alta), y al volumen creciente de nuevos créditos requeridos para mantenerse al día con la combinación de mayores montos a financiar por estudiante y mayor cantidad de nuevos estudiantes que acceden al crédito .

Aún más importante, es que no existe razón alguna para aspirar a un programa de crédito estudiantil renovable o autosuficiente. Los montos provenientes del pago de los créditos estudiantiles no tienen prácticamente nada que ver con los montos que se deberían -o se podrían- otorgar a estudiantes deudores nuevos o repetidos. Al máximo de su eficiencia (e independiente del nuevo capital fiscal) un programa de crédito estudiantil debería aspirar a tener el valor presente descontado del flujo anticipado del pago a futuro en cada cohorte de nuevos créditos que esté lo más cercano posible al valor monetario de esos créditos - descontando solamente la proporción de incumplimientos del Estado y sumando el valor presente de cualquier subsidio deliberadamente incorporado-. No obstante, los gobiernos tendrán que contabilizar anualmente los costos de valor presente de los subsidios y las pérdidas, además de cualquier crédito neto nuevo otorgado.

\section{Consideraciones finales}

El financiamiento de la educación superior en cualquier país y aún más dentro de la perspectiva internacional comparativa es un tema extremadamente complejo, muy influenciado por las historias particulares, la cultura y las corrientes políticas e ideológicas predominantes del momento. Las catorce proposiciones enumeradas 
anteriormente son complejas y matizadas, y llamarlas malentendidos podría resultar un perjuicio para quienes las defienden y para las políticas públicas implementadas en muchos países. Cada una tiene algo de cierto y la mayoría tiene sus defensores serios y reflexivos. No obstante, creo que también existen elementos importantes de malentendido en cada una y que las políticas más efectivas para el financiamiento de la educación superior requieren de un debate adicional y de consideraciones alternativas, las cuales he intentado ofrecer en este ensayo.

\section{Referencias}

Altbach, P. G., Reisberg, L., \& Rumbley, L. E. (2009). Trends in global higher education: Tracking an academic revolution. Paris: Unesco. [A report prepared for the 2009 World Conference on Higher Education].

Barr, N. \& Crawford, I. (2004). Financing higher education, answers from the UK. London and New York: Routledge.

College Board. (2011). Trends in financial aid 2011. Recuperado de http:// trends.collegeboard.org/downloads/Student_Aid_2011.pdf

Johnstone, D. B. \& Marcucci, P. (2010a). Making student loans work in low and middle income countries: Enhancing asset values and tapping private capital. Buffalo: International Comparative Higher Education Finance and Accessibility Project. Recuperado de http://www.gse.buffalo.edu/ org/IntHigherEdFinance

Johnstone, D. B. \& Marcucci, P. (2010b). Financing higher education worldwide: Who pays? Who should pay? Baltimore: The Johns Hopkins University Press.

Harrington, P. E. \& Sum, A. (2010). “College labor shortage in 2018?". New England Board of Higher Education. Recuperado de http://www.nebhe. org/thejournal/college-labor-shortages-in-2018/

Shen, H. \& Ziderman, A. (2009). Student loan plans repayment and recovery: International comparisons. The International Journal of Higher Education and Educational Planning, 57(3), 315-333.

Recibido: 21/10/2015

Aceptado: 21/10/2015 